CARDEMATORI, Daniela Mesquita Leutchuk de; LUZ, Marlise da Rosa. O medo como instrumento de legitimação da atuação repressiva do estado. Revista Eletrônica Direito e Política, Programa de Pós-Graduação Stricto Sensu em Ciência Jurídica da UNIVALI, Itajaí, v.12, n.3, 30 quadrimestre de 2017. Disponível em: www.univali.br/direitoepolitica - ISSN $1980-7791$

\title{
O MEDO COMO INSTRUMENTO DE LEGITIMAÇÃO DA ATUAÇÃO REPRESSIVA DO ESTADO
}

FEAR AS AN INSTRUMENT OF LEGITIMATION OF THE STATE'S REPRESSIVE ACTION

\section{Daniela Mesquita Leutchuk de Cardematori ${ }^{1}$}

\author{
Marlise da Rosa Luz²
}

SUMÁRIO: Introdução; 1 Cultura do medo: uma breve contextualização; 20 medo como instrumento de legitimação da atuação repressiva; 3 Exemplos de medidas estratégicas do estado de legitimação repressiva no plano da legislação; Considerações finais; Referências das fontes citadas

\section{RESUMO}

As cidades contemporâneas vivenciam uma realidade que é reproduzida pela mídia como um espaço em constante situação de emergência, um cenário de constante risco e caos, de desordem e onde a insegurança tomou conta pela eclosão da violência. Com base nessa premissa, a abordagem do presente trabalho inclui uma breve contextualização de cultura do medo, sua origem etimológica e formas de manifestação. A seguir, analisa-se como o medo, ao corromper o senso comum, torna propícia a dominação pela manipulação do imaginário, podendo servir como instrumento de legitimação de métodos estatais criminalizadores e repressivos. Ao fim, apresentam-se exemplos no âmbito do legislativo brasileiro, de medidas formalistas e de natureza autoritária do Estado, especialmente a partir das mobilizações sociais de rua, desde 2013. O estudo adota o método teórico-dedutivo, a partir de levantamentos bibliográficos, artigos e trabalhos específicos, com a finalidade de subsidiar pesquisas e estudos supervenientes sobre o tema.

PALAVRAS-CHAVE: Cultura do Medo; Cultura; Medo; Legitimação; Atuação repressiva

\footnotetext{
${ }^{1}$ Mestre e Doutora em Direito pela UFSC - Florianópolis/SC (1993 e 2001) e Pós-Doutorado junto à UFSC (2015). Atualmente é docente no curso de Direito da Universidade La Salle e professora vinculada ao Programa de Mestrado Direito e Sociedade também da Universidade La Salle de Canoas. Canoas/RS, Brasil. Email:daniela.cademartori@unilasalle.edu.br

2 Mestranda em Direito da Universidade La Salle de Canoas - Linha de Pesquisa: Sociedade e Fragmentação do Direito. Canoas/RS, Brasil. Email: marliseluz@gmail.com
} 
CARDEMATORI, Daniela Mesquita Leutchuk de; LUZ, Marlise da Rosa. O medo como instrumento de legitimação da atuação repressiva do estado. Revista Eletrônica Direito e Política, Programa de Pós-Graduação Stricto Sensu em Ciência Jurídica da UNIVALI, Itajaí, v.12, n.3, 30 quadrimestre de 2017. Disponível em: www.univali.br/direitoepolitica - ISSN $1980-7791$

\section{ABSTRACT}

Contemporary cities experience a reality that is reproduced by the media as a space in constant emergency, a scenario of constant risk and chaos, of disorder and where insecurity has taken over the outbreak of violence. Based on this premise, the approach of the present work includes a brief contextualization of fear culture, its etymological origin and forms of manifestation. Then, it is analyzed how fear, by corrupting common sense, makes domination propitious by the manipulation of the imaginary, and can serve as an instrument of legitimation of state methods that are criminalizing and repressive. Finally, examples are presented in the framework of the Brazilian legislature, of formalist and authoritarian measures of the State, especially from the street social mobilizations, since 2013. The study adopts the theoretical-deductive method, based on bibliographical surveys, Articles and specific works, with the purpose of supporting researches and studies supervenientes on the subject.

KEYWORDS: Culture of Fear; Culture; Fear; Legitimation; Repressive action

\section{INTRODUÇÃO}

A insegurança e o medo, interpretados pelo senso comum da sociedade como decorrências do crescimento e desenvolvimento das cidades, bem como, da violência, da criminalidade e desordem que atemorizam os indivíduos e as relações sociais, são aspectos que cada vez mais inspiram a análise da vida urbana.

Estudos tem evidenciado que esses sentimentos têm sido explorados pela mídia, uma das principais difusoras e formadoras de opiniões, que não economizam em informações sensacionalistas, notícias notadamente mercadológicas, de banalização da violência, tendentes a atemorização do público. O imaginário coletivo de constante ameaça passa, então, a orientar e apontar mudanças no comportamento e na vida das pessoas nas grandes cidades.

Assim, o presente trabalho, ante a necessidade de delimitação da abrangência da concepção de cultura do medo, inicialmente, abordará de modo sucinto, sem o objetivo de esgotar o tema, a contextualização e definições etimológicas das palavras cultura e/do medo. 
CARDEMATORI, Daniela Mesquita Leutchuk de; LUZ, Marlise da Rosa. O medo como instrumento de legitimação da atuação repressiva do estado. Revista Eletrônica Direito e Política, Programa de Pós-Graduação Stricto Sensu em Ciência Jurídica da UNIVALI, Itajaí, v.12, n.3, $3^{\circ}$ quadrimestre de 2017. Disponível em: www.univali.br/direitoepolitica - ISSN $1980-7791$

A seguir, no segundo momento, procurar-se-á evidenciar como o medo, ao corromper (ou fabricar) o senso comum, torna propícia a dominação mediante a manipulação do imaginário, e como esse comportamento poderá ser utilizado como instrumento de legitimação de métodos estatais criminalizadores para garantir a "ordem social".

No último momento, exemplificam-se algumas medidas estratégicas de natureza legislativa, adotadas pelo Estado brasileiro, de modo a legitimar a repressão, especialmente considerando movimentos sociais, como as Jornadas de Junho de 2013, quando um conjunto de projetos de leis foram apresentados difundindo a criminalização de condutas.

Portanto, a partir de uma avaliação teórico-dedutiva, o presente trabalho traz uma abordagem preparatória sobre a cultura do medo e a relação do Estado no reforço dessa concepção na sociedade moderna.

\section{CULTURA DO MEDO: UMA BREVE CONTEXTUALIZAÇÃO}

A sociedade atual cada vez mais manifesta preocupação com a insegurança e o medo, pari passu ao crescimento e desenvolvimento das cidades, normalmente associados à violência, à criminalidade, à desordem, fatos que tem instigado cada vez mais os pesquisadores das ciências sociais a pesquisar e compreender as causas e efeitos dessa realidade.

Inegavelmente, essa preocupação muito decorre da modernidade, atualmente marcada pelas inúmeras interconexões possibilitadas pela crescente rede e fluxos das novas tecnologias da informação e comunicação.

A mídia em geral, através das divulgações da imprensa, tem se mostrado uma das principais influenciadoras e formadoras de opiniões da vida nas cidades, sendo que a concorrência pela maior audiência, muitas vezes está centrada na divulgação de casos sensacionalistas, de maior impacto local, regional ou nacional, e que envolvem violência e criminalidade. 
CARDEMATORI, Daniela Mesquita Leutchuk de; LUZ, Marlise da Rosa. O medo como instrumento de legitimação da atuação repressiva do estado. Revista Eletrônica Direito e Política, Programa de Pós-Graduação Stricto Sensu em Ciência Jurídica da UNIVALI, Itajaí, v.12, n.3, $3^{0}$ quadrimestre de 2017. Disponível em: www.univali.br/direitoepolitica - ISSN $1980-7791$

Débora Pestana já destacou esse enfoque nos seus trabalhos de pesquisa, ressaltando que "a imprensa tem parcela significativa de responsabilidade nesta estigmatização". ${ }^{3}$

Esta constatação da autora generalizou-se. Veja-se a seguinte afirmação:

A mídia tem utilizado mecanismos - 'atrativos' - para fomentar o medo. Ou melhor, explora os fatos ocorridos no cotidiano em prol do aterrorizamento da sociedade com comentários, muitas das vezes inescrupulosos, com o objetivo de 'manipular a informação' com vistas a fomentar a aplicação do Direito Penal do Medo. 4

Ou seja, as cidades contemporâneas vivenciam uma realidade que, via de regra, é reproduzida pela mídia como um espaço em constante situação de emergência, um cenário de constante risco e caos, de desordem e onde a insegurança tomou conta.

Nessa perspectiva, consolida-se a Cultura do Medo, sustentada e perpetuada como um clima de pânico, de constante vigilância, alimentada pelo imaginário coletivo e que desencadeiam consecutivas alterações no comportamento humano e nas relações sociais.

Antes de adentrar efetivamente na discussão que abordará o presente trabalho, é importante que se tenha em mente que tanto a palavra "cultura" como a palavra "medo" são palavras que possuem uma etimologia complexa e que podem ser analisadas sob vários aspectos e abordagens, na atualidade.

3 PASTANA, Débora. Medo, controle e segregação espacial: reflexões sobre a configuração urbana da cidade de São Paulo no atual estágio da modernidade. Mediações - Revista de Ciências Sociais. Londrina, v. 10, n. 2, p.183-198, jul/dez 2005. Disponível em:

http://www.uel.br/revistas/uel/index.php/mediacoes/article/view/2172/1864. Acesso em: 29 set. 2016.

4 GALO, Janaina Soares; ANDRADE, Vanessa Faullame. Tiros em Columbine (Bouling for Columbine). Revista Liberdades: São Paulo, p. 142-143, dez. 2011 (Edição especial). Disponível em:

http://www.ibccrim.org.br/revista_liberdades_artigo/108-RESENHA-DE-FILME. Acesso em $01 / 12 / 2016$ 
CARDEMATORI, Daniela Mesquita Leutchuk de; LUZ, Marlise da Rosa. O medo como instrumento de legitimação da atuação repressiva do estado. Revista Eletrônica Direito e Política, Programa de Pós-Graduação Stricto Sensu em Ciência Jurídica da UNIVALI, Itajaí, v.12, n.3, 30 quadrimestre de 2017. Disponível em: www.univali.br/direitoepolitica - ISSN $1980-7791$

Zygmunt Bauman (2008) em se livro "Medo Líquido", propõe dissecar os medos que os indivíduos vivenciam na chamada "modernidade líquida". Trata-se de um estudo complexo sobre as origens e os obstáculos que dificultam a compreensão dos fatos, além de analisar os mecanismos capazes de deter a influência do medo sobre nossas vidas.

Para o autor as origens das inquietações mundanas não se limitam ao medo do risco à vida. Sustenta que os humanos "conhecem algo mais além disso" ${ }^{\prime \prime}$, referindo-se a um tipo de medo que se reproduz internamente, um sentimento que independe de existir uma ameaça direta e que condiciona o comportamento humano. Ele o chama de medo de "segundo grau" ou "medo derivado".

O medo derivado é uma estrutura mental estável que pode ser mais bem descrita como o sentimento de ser suscetível ao perigo. Uma sensação de insegurança (o mundo está cheio de perigos que pode se abater sobre nós a qualquer momento como algum ou nenhum aviso) e vulnerabilidade (no caso de o perigo se concretizar, haverá pouca ou nenhuma chance de fugir ou de se defender com sucesso; o pressuposto da vulnerabilidade aos perigos depende mais da falta de confiança nas defesas disponíveis do que do volume ou da natureza das ameaças reais). 6

O referido autor ainda ressalta que os perigos que o ser humano teme são basicamente três tipos: o que ameaça sua integridade física, o seu sustento (emprego, renda, como sobreviveria em caso de invalidez ou velhice) e o da exclusão social, que pode ameaçar o seu lugar no mundo, sua identidade. $\mathrm{E}$ conclui também, a partir da análise de outros estudos, que aquele medo derivado, normalmente está desacoplado em relação a esses perigos: poderá sobrevir um sentimento de insegurança e vulnerabilidade independente da existência direta daqueles perigos.

\footnotetext{
${ }^{5}$ BAUMAN, Zygmunt. Medo Líquido. Tradução de Carlos Alberto Medeiros, Rio de Janeiro: Zahar, 2008. p. 09.

6 BAUMAN, Zygmunt. Medo Líquido. p. 09.
} 
CARDEMATORI, Daniela Mesquita Leutchuk de; LUZ, Marlise da Rosa. O medo como instrumento de legitimação da atuação repressiva do estado. Revista Eletrônica Direito e Política, Programa de Pós-Graduação Stricto Sensu em Ciência Jurídica da UNIVALI, Itajaí, v.12, n.3, $3^{0}$ quadrimestre de 2017. Disponível em: www.univali.br/direitoepolitica - ISSN $1980-7791$

E refere que "O medo nos estimula a assumir uma ação defensiva, e isso confere proximidade, tangibilidade e credibilidade às ameaças, genuínas ou supostas, de que ele presumivelmente emana."7. Ou seja, o próprio ser humano legitima, cria para si uma ilusão para justificá-lo.

Contudo, é importante recordar que "[...]o medo sempre acompanhou o homem, haja vista a busca permanente de unidade, coesão e a organização em grupo para se fortalecer e se proteger, ou seja, para enfrentar e eliminar as causas do medo." 8 Pode-se dizer que a sobrevivência humana esteve vinculada ao longo dos tempos, pelo receio do medo, como uma sinalização da percepção de perigo e autoproteção. O próprio Bauman reconhece que "o medo é um sentimento conhecido de toda criatura viva". ${ }^{9}$

Analisando essa temática a partir das concepções teóricas de Anthony Giddens, que tem trazido importantes contribuições a respeito da modernidade e de seus desdobramentos para a vida social, pode-se dizer que "vivemos atualmente a radicalização e a expansão da modernidade da sociedade" e que "[...] estamos num universo que não compreendemos plenamente e que está fora de nosso controle". ${ }^{10}$ Há uma identificação de que a racionalidade humana não consegue manter na atualidade o controle das ações, a previsibilidade, nem dos próprios seres humanos.

Ainda, na perspectiva do sociólogo britânico, "[...] a grande experiência da modernidade repleta de perigos globais, não é de maneira alguma o que os pais do Iluminismo tinham em mente quando falaram da importância de

\footnotetext{
7 BAUMAN, Zygmunt. Medo Líquido. p. 173.

8 PASTANA, Débora. Medo, controle e segregação espacial: reflexões sobre a configuração urbana da cidade de São Paulo no atual estágio da modernidade. p. 183.

9 BAUMAN, Zygmunt. Medo Líquido. p. 09

10 OLIVEIRA, Fabrício Roberto Costa; ZANGELMI, Arnaldo José. Modernidade e Reflexividade: Anthony Giddens e a interpretação do mundo contemporâneo. Isegoria Ação Coletiva em Revista. Viçosa: Universidade Federal de Viçosa, 2011, v. 1, n. 2, p 111123, set. de 2011/fev. de 2012.
} 
CARDEMATORI, Daniela Mesquita Leutchuk de; LUZ, Marlise da Rosa. O medo como instrumento de legitimação da atuação repressiva do estado. Revista Eletrônica Direito e Política, Programa de Pós-Graduação Stricto Sensu em Ciência Jurídica da UNIVALI, Itajaí, v.12, n.3, 30 quadrimestre de 2017. Disponível em: www.univali.br/direitoepolitica - ISSN $1980-7791$

contestar a tradição."11 Ou seja, o autor procura deixar claro que o desenvolvimento das instituições modernas e os novos modos de vida tem também um lado preocupante, que se relaciona com o desconhecido. O ser humano teme o que não pode administrar, o que não pode compreender, típico da era moderna.

Nesse aspecto, Bauman ${ }^{12}$, transcreve os ensinamentos de Manuel Castells e diz o seguinte:

[...] nosso sentimento agudo de insegurança deriva não tanto da carência de proteção quanto da inescapável 'falta de clareza de seu escopo' (ombre portée) em um tipo de universo social que, como o nosso, 'foi organizado em torno da infindável busca de proteção e da frenética busca de segurança [...] nossa "obsessão com segurança', assim como nossa intolerância a qualquer brecha ainda que mínima no seu fornecimento, que se torna a fonte mais prolífica, autorenovável e provavelmente inexaurível de nossa ansiedade e de nosso medo.

É esse reforço de pensamento que persegue o indivíduo ao longo de sua existência, que acaba consolidando a cultura do medo.

A palavra cultura é polissêmica e seu conceito, no aspecto sociológico, está intimamente vinculado às formas de vidados membros e grupos dentro da sociedade. Anthony Giddens, nos seus ensinamentos explica o conceito de cultura:

Quanto os sociólogos se referem à cultura, estão preocupados com aqueles aspectos da sociedade humana que são antes aprendidos do que herdados. Esses elementos culturais são compartilhados por membros da sociedade e tornam possível a cooperação e a comunicação. Forma o contexto comum em que os indivíduos numa sociedade vivem as suas vidas. A

11 GIDDENS, Anthony. A vida em uma sociedade pós-tradicional. In: BECK, Ulrich; GIDDENS, Anthony; LASH, Scott. Tradução de Magda Lopes. Modernização Reflexiva: política, tradição e estética na ordem social moderna. São Paulo: Editora da Universidade Estadual Paulista, 1997. p. 73-134.

12 BAUMAN, Zygmunt. Medo Líquido. p. 169. 
CARDEMATORI, Daniela Mesquita Leutchuk de; LUZ, Marlise da Rosa. O medo como instrumento de legitimação da atuação repressiva do estado. Revista Eletrônica Direito e Política, Programa de Pós-Graduação Stricto Sensu em Ciência Jurídica da UNIVALI, Itajaí, v.12, n.3, $3^{\circ}$ quadrimestre de 2017. Disponível em: www.univali.br/direitoepolitica - ISSN $1980-7791$

cultura de uma sociedade compreende tanto aspectos intangíveis - as crenças, as ideias e os valores que formam o conteúdo da cultura - como também aspectos tangíveis - os objetivos, os símbolos u a tecnologia que representam esse conteúdo. ${ }^{13}$

A cultura do medo, nesses aspectos, configura-se como "[...]a expressão das necessidades historicamente condicionadas de um grupo social e de seus indivíduos, e como referência à totalidade de características de uma sociedade."14 Ou seja, reproduz inquietações, constantes e dinâmicas que se desenvolvem no comportamento e relações sociais.

[...]representa a somatória dos valores, comportamentos e do senso comum que, associados à questão da criminalidade, reproduz a idéia hegemônica de insegurança $e$, com isso, perpetua uma forma de dominação marcada pelo autoritarismo e pela rejeição aos princípios democráticos. ${ }^{15}$

Uma outra faceta desta cultura é a de que os medos estão representados "por todo o espectro de atividades existenciais. Suas fontes permanecem ocultas e [...] o mistério que envolve essas fontes aumenta ainda mais seu potencial de inspirar o medo". ${ }^{16}$

Com isso, a cultura do medo é compreendida não apenas a partir do medo individual, mas sim, um medo socialmente partilhado, que mina o imaginário da sociedade e que transforma os comportamentos, as relações sociais, repercutindo, inclusive, com a diminuição da vida democrática.

13 GIDDENS, Anthony. Sociologia. Tradução de Sandra Regina Netz. 4. ed. Porto Alegre: Artmed, 2005, p. 38.

14 PASTANA, Débora. Medo, controle e segregação espacial: reflexões sobre a configuração urbana da cidade de São Paulo no atual estágio da modernidade. p. 190.

15 PASTANA, Débora. Medo, controle e segregação espacial: reflexões sobre a configuração urbana da cidade de São Paulo no atual estágio da modernidade. p. 183.

16 BAUMAN, Zygmunt. Medo Líquido. p. 184. 
CARDEMATORI, Daniela Mesquita Leutchuk de; LUZ, Marlise da Rosa. O medo como instrumento de legitimação da atuação repressiva do estado. Revista Eletrônica Direito e Política, Programa de Pós-Graduação Stricto Sensu em Ciência Jurídica da UNIVALI, Itajaí, v.12, n.3, $3^{\circ}$ quadrimestre de 2017. Disponível em: www.univali.br/direitoepolitica - ISSN $1980-7791$

\section{O MEDO COMO INSTRUMENTO DE LEGITIMAÇÃO DA ATUAÇÃO REPRESSIVA}

O discurso do medo, assim compreendido como um terror social e que passa a dominar o senso comum, traz consigo, um conjunto de consequências, como 0 isolamento, 0 desinteresse das práticas comunitárias, a negligência coletiva e aos propósitos democráticos.

Cada vez mais, na cultura capitalista e de consumo, os indivíduos tendem a se cercar de todos os meios, tecnologias, recursos que entendem como sistemas de segurança.

Na maioria das situações, a opção por condomínios fechados, muros altos, limitação de circulação em determinadas áreas, locais ou bairros, propõe espaços públicos delimitados, exclusivos, em que os indivíduos procuram se proteger dos inúmeros inimigos que the rodeiam ou que somente existem no imaginário coletivo.

Em verdade, essa arquitetura que se forma e se desenvolve nas grandes cidades, é reflexo da sensação de insegurança e de medo, que acaba conduzindo a adoção de determinados comportamentos.

Debora Regina Pestana denomina essas feições da cidade atual como "arquitetura do medo' - muros altos, cercas em volta das residências, alarmes e sofisticados sistemas de segurança". Refere ainda, que paralelamente a essa tendência, emergem "fenômenos correlatos: crescimento visível das empresas privadas de vigilância, elevada quantidade de armas de fogo em circulação, êxodo de zonas e regiões onde o risco de se transitar sozinho pressupõe-se elevado, além de outros mecanismos de autoproteção". ${ }^{17}$

17 PASTANA, Débora Regina. Medo e opinião pública no Brasil contemporâneo. Revista Estudos de Sociologia, Araraquara, v. 12, n. 22, p. 91-116, 2007. Disponível em: http://seer.fclar.unesp.br/estudos/article/view/350/214. Acesso em: 16 mar. 2016. 
CARDEMATORI, Daniela Mesquita Leutchuk de; LUZ, Marlise da Rosa. O medo como instrumento de legitimação da atuação repressiva do estado. Revista Eletrônica Direito e Política, Programa de Pós-Graduação Stricto Sensu em Ciência Jurídica da UNIVALI, Itajaí, v.12, n.3, 30 quadrimestre de 2017. Disponível em: www.univali.br/direitoepolitica - ISSN $1980-7791$

Mas a cultura do medo enraizada na sociedade poderá conduzir ainda, outras formas de "defesa", como a conivência com a coerção ilegítima:

Atualmente observamos que a exigência fundamental desta sociedade aterrorizada é um rigor punitivo traduzido em penas severas para os transgressores e a criminalização generalizada de condutas. A cultura do medo que se criou em torno da criminalidade provoca um generalizado desejo de punição, uma intensa busca de repressão e uma obsessão por segurança. A lei passa a ser a tábua de salvação da sociedade e quanto maior for a sua dureza, mais satisfeita ela estará. ${ }^{18}$

Bauman também esclarece o assunto, apresentando uma lógica para tal situação:

Enquanto a proteção pessoal se torna um grande ponto de venda, talvez o maior, nas estratégias de marketing de mercadorias de consumo, a garantia da 'lei $e$ ordem', cada vez mais confinada à promessa de proteção pessoal, se tornou um grande ponto de venda, talvez o maior, tanto nos manifestos políticos quanto nas campanhas eleitorais $[\ldots]^{19}$

O medo, ao corromper (ou fabricar) o senso comum, torna propícia a dominação mediante a manipulação do imaginário, e poderá servir como instrumento de legitimação do uso de métodos estatais criminalizadores, em nítida repressão do Estado, já que titular da competência ou monopólio para garantir a "ordem social".

Para pensar a ideia do medo como instrumento de legitimação de dominação é necessário ter em mente, inicialmente, que ele se constitui a partir das incertezas do indivíduo, pois sua constituição se dá pelo desconhecimento, ou seja, pela presença da ausência. Assim, a partir dessa ausência é que se cria o desejo e,

\footnotetext{
18 PASTANA, Débora. Medo, controle e segregação espacial: reflexões sobre a configuração urbana da cidade de São Paulo no atual estágio da modernidade. p. 193

19 BAUMAN, Zygmunt. Medo Líquido. p. 188.
} 
CARDEMATORI, Daniela Mesquita Leutchuk de; LUZ, Marlise da Rosa. O medo como instrumento de legitimação da atuação repressiva do estado. Revista Eletrônica Direito e Política, Programa de Pós-Graduação Stricto Sensu em Ciência Jurídica da UNIVALI, Itajaí, v.12, n.3, $3^{0}$ quadrimestre de 2017. Disponível em: www.univali.br/direitoepolitica - ISSN $1980-7791$

consequentemente, a necessidade de se ter a segurança. ${ }^{20}$

Em síntese, os indivíduos passam a ter um entendimento de que, quanto maior a atuação disciplinadora e emergencial do Estado, maior será a chance de "tranquilidade da vida social", de que o futuro será igual ao presente, de que se manterá o status quo.

Ou seja, consolida-se a "violência institucional", ou ainda, o "monopólio da violência legítima", em que o Estado, no exercício da sua competência legal, utiliza de aparatos criminalizadores que "[...] dada sua potencialidade, [...] pede certo grau de legitimação só alcançável através do pânico."21

Passa a prevalecer na sociedade "uma ideologização que dá ao Estado a legitimação necessária à garantia da ordem, possibilitando uma organização social rígida, hierarquizada e sem oposição (atomizada)."22

Os indivíduos tendem a manter-se obedientes, na medida em que se sentem incluídos, fazendo parte do sistema e pensando de acordo com ele. Difunde-se a ideia de que está assegurada a igualdade de interpretação, de modo que os interesses individuais são direcionados aos objetivos estruturais da sociedade.

Fundada a partir da lógica da dominação, a sociedade interpreta os fatos, conforme a ideologia vigente naquele momento histórico, ou seja, a lógica hegemônica do grupo dominante deve prevalecer, difundindo a ideia principal através de pequenas justificações, as quais, permitirão ante a presença do fato indesejado, mas real, que parcela de sua liberdade sejam reprimidas a fim de manter (ou restaurar) a

20 GRAZIANO SOBRINHO, Sergio Francisco Carlos. Cultura do Medo. In: SIDEKUM, Antonio; WOLKMER, Antonio Carlos; RADAELLI, Samuel Manica (Orgs.). Enciclopédia latino-americana dos direitos humanos. Nova Petrópolis, RS: Nova Harmonia, 2016, p. 139.

21 PASTANA, Débora. Medo, controle e segregação espacial: reflexões sobre a configuração urbana da cidade de São Paulo no atual estágio da modernidade. p. 193.

22 GRAZIANO SOBRINHO, Sergio Francisco Carlos. Cultura do Medo. p. 141. 
CARDEMATORI, Daniela Mesquita Leutchuk de; LUZ, Marlise da Rosa. O medo como instrumento de legitimação da atuação repressiva do estado. Revista Eletrônica Direito e Política, Programa de Pós-Graduação Stricto Sensu em Ciência Jurídica da UNIVALI, Itajaí, v.12, n.3, $3^{\circ}$ quadrimestre de 2017. Disponível em: www.univali.br/direitoepolitica - ISSN $1980-7791$

ordem, ainda que em troca de arbitrariedade ou opressão. ${ }^{23}$

Sendo assim, a cultura do medo é absorvida pela sociedade e reflete exatamente a produção do imaginário social ideologicamente efetivado e divulgado. "Cada sociedade produce su tipo de espacio y cultiva sus próprios miedos" 24 , de modo que a opção ideológica de proteção pelo Estado, é renovada a cada ameaça de tomada de espaço pelas movimentações populares, pela oposição à conjuntura apresentada e difundida.

Maria José Gonzáles Ordovás, também refere que a reclamação da sociedade para que tudo seja seguro reproduz o chamado "despotismo administrativo", mencionado por Alexis de Tocqueville:

En nuestros días hay mucha gente que se acomoda, muy fácilmente, a esta espécie de compromisso entre el despotismo administrativo y la soberania del Pueblo, y que piensa que ha garantizado bastante la libertad de los individuos cuando es el poder nacional a quien la entrega [...] Combinan la centralización y la soberania del Pueblo. Eso les proporciona cierto descanso. Se consuelan por esta bajo tutela. Pensando que ellos mismos han elegido a sus tutores. ${ }^{25}$

Assim, a difusão do medo, do caos, da desordem e insegurança tem servido para justificar estratégias de disciplinamento e de justificativa ao Estado para adotar medidas simbólicas cada vez mais autoritárias, com o intuito de transmitir uma ideia de fortalecimento da ordem.

${ }^{23}$ GRAZIANO SOBRINHO, Sergio Francisco Carlos. Cultura do Medo, p. 141.

24 GONZÁLEZ ORDOVÁS, Maria José. La Ciudad em Clave de Riesgo. In: ROSILLO MARTÍNEZ, Alejandro et al. Teoria crítica dos direitos humanos no século XXI. Porto Alegre: EDIPUCRS, 2008. p. 465

25 GONZÁLEZ ORDOVÁS, Maria José. La Ciudad em Clave de Riesgo. p. 449. 
CARDEMATORI, Daniela Mesquita Leutchuk de; LUZ, Marlise da Rosa. O medo como instrumento de legitimação da atuação repressiva do estado. Revista Eletrônica Direito e Política, Programa de Pós-Graduação Stricto Sensu em Ciência Jurídica da UNIVALI, Itajaí, v.12, n.3, 30 quadrimestre de 2017. Disponível em: www.univali.br/direitoepolitica - ISSN $1980-7791$

\section{EXEMPLOS DE MEDIDAS ESTRATÉGICAS DO ESTADO DE LEGITIMAÇÃO REPRESSIVA NO PLANO DA LEGISLAÇÃO}

O Brasil desde as manifestações populares conhecidas como as Jornadas de Junho de $2013^{26}$ tem vivenciado a eclosão de uma série de movimentos populares, com as mais variadas reivindicações e discordâncias ao contexto sociopolítico e socioeconômico do Brasil.

Referidas mobilizações, como regra, são amplamente veiculadas pela imprensa e podem ser associadas à "leis reativas, políticas públicas, atuações policiais ou histórias midiáticas que provocaram no público uma preocupação exagerada, medo e raiva em relação a aparentes riscos à ordem social." 27

Ou seja, com enfoque na existência de uma exacerbada violência, uma das formas encontradas pelo Estado para administrar e conter as massas populares de insatisfeitos tem sido a utilização do sistema de controle social, do tipo penal: a criminalização de condutas.

$\mathrm{Na}$ abordagem feita por Renata, Alexandre e Germano sobre as jornadas de 2013, essa temática foi analisada a partir do conceito de "Empreendedores Morais", assim compreendidos como "aqueles que tomam a iniciativa de

\footnotetext{
26 O nome, Jornada de Junho em si induz ao erro, uma vez que as movimentações começaram muito antes disso, e as repercussões permanecem até o dia de hoje (Movimento Passe Livre 2013). O início das movimentações estava relacionado ao aumento das passagens de ônibus em Porto Alegre, quando vários grupos reuniram-se para buscar [...] a redução de preço da passagem e manutenção da meia passagem estudantil e passe livre para os idosos.[...]. Essa mobilização ganhou significativa importância quando suspendeu o aumento das passagens em abril de 2013. E ao mesmo tempo, ao longo de todo o país, foram se alastrando manifestações com expressivo número de pessoas na participação com as mais variadas recomendações. COSTA, Renata Almeida da. SCHWARTZ, Germano. FLECK, Alexandre Brandão. As respostas do Direito e da política às jornadas de junho: uma análise da jucialização e do processo de criminalização na cidade de Porto Alegre. In: Revista Brasileira de Ciências Criminais. Vol. 115. Jul-ago/2015. São Paulo: RT, 2015, p. 291310.

27 COSTA, Renata Almeida da; SCHWARTZ, Germano; FLECK, Alexandre Brandão. As respostas do Direito e da política às jornadas de junho: uma análise da jucialização e do processo de criminalização na cidade de Porto Alegre. p. 298.
} 
CARDEMATORI, Daniela Mesquita Leutchuk de; LUZ, Marlise da Rosa. O medo como instrumento de legitimação da atuação repressiva do estado. Revista Eletrônica Direito e Política, Programa de Pós-Graduação Stricto Sensu em Ciência Jurídica da UNIVALI, Itajaí, v.12, n.3, $3^{0}$ quadrimestre de 2017. Disponível em: www.univali.br/direitoepolitica - ISSN $1980-7791$

criar e estabelecer as regras, assim como, aqueles que garantem que elas (sic) sejam cumpridas e respeitadas." 28

No referido artigo, os autores buscaram "identificar de que forma o sistema político e o sistema legal lidaram com os movimentos sociais de junho através da análise dos processos de criminalização primária e secundária na Cidade de Porto Alegre" 29 , e nesse aspecto, também é possível identificar que desde esse momento, as mobilizações foram interpretadas pelo Estado como oposição à uma ideologia de tranquilidade social. ${ }^{30}$

A desmobilização do movimento a partir do medo provocado pelo aumento da violência e dos confrontos com a polícia, reforçaram concepções como caos urbano, desordem, pânico, desobediência, e nesse enfoque, a emergência da ideia de legitimação do poder estatal pela atuação repressiva contra essas condutas desordeiras.

Nessa seara, desde o ano de 2013 é possível identificar-se que o Estado passa a criar mecanismos legais de criminalização desses movimentos, que servem também para renovar a sua legitimação de condutas opressoras.

Esses mecanismos de criminalização podem ser exemplificados em vários projetos de lei que estão em tramitação no Congresso Nacional ${ }^{31}$ e que tiveram sua origem desde o ano de 2013 , sendo a ampla maioria voltada à disciplina de condutas, coibições e limitações das mobilizações populares.

28 COSTA, Renata Almeida da. SCHWARTZ, Germano. FLECK, Alexandre Brandão. As respostas do Direito e da política às jornadas de junho: uma análise da jucialização e do processo de criminalização na cidade de Porto Alegre. p. 296.

29 COSTA, Renata Almeida da. SCHWARTZ, Germano. FLECK, Alexandre Brandão. As respostas do Direito e da política às jornadas de junho: uma análise da jucialização e do processo de criminalização na cidade de Porto Alegre. p. 300

30 GRAZIANO SOBRINHO, Sergio Francisco Carlos. Cultura do Medo. p. 141.

31 Á exceção do Projeto de Lei no 6.307/2013, que foi convertido em Lei Ordinária no 13.260/2016, todos os demais projetos ainda estão em andamento interno do processo legislativo. 
CARDEMATORI, Daniela Mesquita Leutchuk de; LUZ, Marlise da Rosa. O medo como instrumento de legitimação da atuação repressiva do estado. Revista Eletrônica Direito e Política, Programa de Pós-Graduação Stricto Sensu em Ciência Jurídica da UNIVALI, Itajaí, v.12, n.3, $3^{\circ}$ quadrimestre de 2017. Disponível em: www.univali.br/direitoepolitica - ISSN $1980-7791$

\begin{tabular}{|c|c|}
\hline $\begin{array}{l}\text { Projeto de Lei } \\
n^{\circ} 451 / 2013\end{array}$ & $\begin{array}{l}\text { Ementa }^{32} \\
\text { Altera a Lei no } 7.170 \text {, de } 14 \text { de dezembro de } 1983 \text {, o Decreto-Lei no } \\
2.848 \text {, de } 7 \text { de dezembro de } 1940 \text { - Código Penal, e a Lei no } 12.850 \text {, } \\
\text { de } 2 \text { de agosto de } 2013 \text {, para prevenir e reprimir a violência e o } \\
\text { vandalismo nas manifestações públicas coletivas. }\end{array}$ \\
\hline $\begin{array}{l}\text { Projeto de Lei } \\
\text { no } 499 / 2013\end{array}$ & $\begin{array}{l}\text { Ementa }{ }^{\mathbf{3 3}} \\
\text { Define crimes de terrorismo e dá outras providências. Também } \\
\text { chamada de Projeto de Lei Antirrerrorismo. }\end{array}$ \\
\hline $\begin{array}{l}\text { Projeto de Lei } \\
\text { no }^{\circ} 508 / 2013\end{array}$ & $\begin{array}{l}\text { Ementa } \\
\text { Tipifica como crime de vandalismo a promoção de atos coletivos de } \\
\text { destruição, dano ou incêndio em imóveis públicos ou particulares, } \\
\text { equipamentos urbanos, instalações de meios de transporte de } \\
\text { passageiros, veículos e monumentos. }\end{array}$ \\
\hline $\begin{array}{l}\text { Projeto de Lei } \\
n^{\circ} \\
5.531 / 2013\end{array}$ & $\begin{array}{l}\text { Ementa }^{35} \\
\text { Acresce dispositivo ao Decreto-Lei no } 2.848 \text {, de } 7 \text { de dezembro de } \\
1940 \text { - Código Penal. } \\
\text { Tipifica o crime de atentado contra a segurança do transporte } \\
\text { rodoviário. }\end{array}$ \\
\hline $\begin{array}{l}\text { Projeto de Lei } \\
n^{\circ} \\
6.307 / 2013\end{array}$ & $\begin{array}{l}\text { Ementa }{ }^{36} \\
\text { Altera o Decreto-Lei no } 2.848 \text {, de } 7 \text { de dezembro de } 1940 \text { - Código } \\
\text { Penal. } \\
\text { Atribui tratamento diferenciado para o agente que pratica atos de } \\
\text { vandalismo em manifestações públicas. }\end{array}$ \\
\hline $\begin{array}{l}\text { Projeto de Lei } \\
\text { no } \\
2.016 / 2015\end{array}$ & $\begin{array}{l}\text { Ementa }{ }^{37} \mathbf{B}^{38} \\
\text { Altera a Lei no } 12.850 \text {, de } 2 \text { de agosto de } 2013 \text {, e a Lei no } 10.446 \text {, } \\
\text { de } 8 \text { de maio de } 2002 \text {, para dispor sobre organizaços terroristas. }\end{array}$ \\
\hline
\end{tabular}

32 BRASIL. Projeto de lei no 451/2013. Disponível em< https://www25.senado.leg.br/web/atividade/materias/-/materia/115089> Acesso em $16 / 12 / 2016$.

33 BRASIL. Projeto de lei no 499/2013. Disponível em< <https://www25.senado.leg.br/web/atividade/materias/-/materia/115549> Acesso em $16 / 12 / 2016$.

34 BRASIL. Projeto de lei no 508/2013. Disponível em: <https://www25.senado.leg.br/web/atividade/materias/-/materia/115638>. Acesso em $16 / 12 / 2016$.

35 BRASIL. Projeto de lei no 5.531/2013. Disponível em: <http://www.camara.gov.br/proposicoesWeb/fichadetramitacao?idProposicao $=576142>$ Acesso em 16/12/2016.

36 BRASIL. Projeto de lei no 6.307/2013. Disponível em: <http://www.camara.gov.br/proposicoesWeb/fichadetramitacao?idProposicao=591175> Acesso em 16/12/2016.

37 BRASIL. Projeto de lei no 6.307/2013. Disponível em: <http://www.camara.gov.br/proposicoesWeb/fichadetramitacao?idProposicao=1514014> Acesso em 16/02/2016.

38 Esse projeto de lei transformado na Lei Ordinária 13.260/2016 - BRASIL. Lei Ordinária no 13.260 de 16 de março de 2016. Regulamenta o disposto no inciso XLIII do art. 5o da Constituição Federal, disciplinando o terrorismo, tratando de disposições investigatórias e processuais e reformulando o conceito de organização terrorista; e altera as Leis nos 7.960, de 21 de dezembro de 1989, e 12.850, de 2 de agosto de 2013. Diário Oficial da União, Poder Executivo, Brasília, DF, 17 mar 2016 - Edição extra e retificada em 18.3.2016,, Página 1 . 
CARDEMATORI, Daniela Mesquita Leutchuk de; LUZ, Marlise da Rosa. O medo como instrumento de legitimação da atuação repressiva do estado. Revista Eletrônica Direito e Política, Programa de Pós-Graduação Stricto Sensu em Ciência Jurídica da UNIVALI, Itajaí, v.12, n.3, 30 quadrimestre de 2017. Disponível em: www.univali.br/direitoepolitica - ISSN $1980-7791$

Os projetos de leis acima destacados, caracterizam-se como propostas apresentadas pelo Estado, e que visam a criminalização de condutas, de regra relacionadas a movimentos populares.

Recentemente, inclusive, por conta de mobilizações sociais ocorridas em razão de denúncias de corrupção contra a governança do atual Presidente Michel Temer, foi publicado Decreto Presidencial ${ }^{39}$ que autorizou o emprego das Forças Armadas para a garantia da lei e da ordem no distrito federal. Mais um exemplo do exercício do poder Estatal que utiliza a criminalização de condutas em favor da legitimação do poder repressivo.

A lógica decorre do interesse do Estado em deixar evidente que ele mantém o monopólio da ordem pública. Assume e empodera-se no papel de manutentor da segurança e ordem social, e com isso, vale-se da competência legal para criminalizar condutas.

Esse entendimento, de legitimação da atuação repressiva com foco na política de segurança pública, promove a criminalização de condutas civis, e ainda, um desencorajamento de movimentos sociais através da difusão do medo na sociedade.

\section{CONSIDERAÇÕES FINAIS}

A mídia em geral, através das divulgações da imprensa, tem se mostrado uma das principais influenciadoras e formadoras de opiniões da vida nas cidades. Habitualmente, o conjunto de informações envolvendo a criminalidade e violência, não reproduz a efetiva realidade, mas sim, informações distorcidas e estereotipadas.

Esse mecanismo de divulgação de fatos e ocorrências violentas, atemorizam a sociedade, que os assimila como um temor coletivo, disseminado. Emerge um senso comum, de inquietações, constantes e dinâmicas que minam o

\footnotetext{
39 BRASIL. Decreto de 24 de maio de 2017. Autoriza o emprego das Forças Armadas para a Garantia da Lei e da Ordem no Distrito Federal. Revogado pelo Decreto de 25 de maio de 2017. Disponível em <http://www.planalto.gov.br/ccivil_03/_Ato20152018/2017/Dsn/Dsn14464.htm> Acesso em 11/06/2017.
} 
CARDEMATORI, Daniela Mesquita Leutchuk de; LUZ, Marlise da Rosa. O medo como instrumento de legitimação da atuação repressiva do estado. Revista Eletrônica Direito e Política, Programa de Pós-Graduação Stricto Sensu em Ciência Jurídica da UNIVALI, Itajaí, v.12, n.3, $3^{\circ}$ quadrimestre de 2017. Disponível em: www.univali.br/direitoepolitica - ISSN $1980-7791$

imaginário da sociedade e que transformam os comportamentos, as relações sociais.

O medo em sociedade atualmente pode ser identificado nas estruturas e arquiteturas urbanísticas. A opção por condomínios fechados, muros altos, limitação de circulação em determinadas áreas, locais ou bairros, propõe espaços públicos delimitados, exclusivos, em que os indivíduos procuram se proteger dos inúmeros inimigos que Ihe rodeiam ou que somente existem no imaginário coletivo.

Essa realidade evidencia o efeito do medo associado aos fatos noticiados pela imprensa, e é a seara propícia a dominação mediante a manipulação do imaginário, quando a vulnerabilidade passa a ser utilizada como instrumento de legitimação do uso de métodos estatais criminalizadores.

Em síntese, os indivíduos passam a ter um entendimento de que, quanto maior a atuação disciplinadora e emergencial do Estado, maior será a chance de "tranquilidade da vida social", de que o futuro será igual ao presente, de que se manterá o status quo.

Consolida-se a "violência institucional", ou ainda, o "monopólio da violência legítima", em que o Estado, no exercício da sua competência legal, utiliza aparatos criminalizadores, a partir do pânico, do medo imaginário e coletivo.

Desde o ano de 2013, a partir de mobilizações populares nacionais, quando a sociedade apresentou várias reivindicações e discordâncias ao contexto sociopolítico e socioeconômico, tem-se identificado o uso, pelo Estado, de mecanismos legais de criminalização primária e secundária.

Esses mecanismos de criminalização, podem ser exemplificados em vários projetos de lei que estão em tramitação no Congresso Nacional, que tem sua origem desde 2013, sendo a ampla maioria voltada a coibições e limitações das manifestações populares. 
CARDEMATORI, Daniela Mesquita Leutchuk de; LUZ, Marlise da Rosa. O medo como instrumento de legitimação da atuação repressiva do estado. Revista Eletrônica Direito e Política, Programa de Pós-Graduação Stricto Sensu em Ciência Jurídica da UNIVALI, Itajaí, v.12, n.3, $3^{\circ}$ quadrimestre de 2017. Disponível em: www.univali.br/direitoepolitica - ISSN $1980-7791$

Portanto, é neste enfoque que se identifica o uso do medo e do imaginário coletivo como meio e instrumento de legitimação da atuação repressiva, bem como, como uma estratégia ao desencorajamento de movimentos sociais.

\section{REFERÊNCIAS DAS FONTES CITADAS}

BAUMAN, Z. Medo Líquido. Tradução de Carlos Alberto Medeiros, Rio de Janeiro: Zahar, 2008.

COSTA, Renata Almeida da; SCHWARTZ, Germano. FLECK, Alexandre Brandão. As respostas do Direito e da política às jornadas de junho: uma análise da judicialização e do processo de criminalização na cidade de Porto Alegre. Revista Brasileira de Ciências Criminais. São Paulo, RBCCrim, v. 23, n. 115, p. 291-307, jul./ago. 2015. Disponível em: <http://bdjur.stj.jus.br/jspui/handle/2011/93931> Acesso em: 24 nov. 2016.

GALO, Janaina Soares; ANDRADE, Vanessa Faullame. Tiros em Columbine (Bouling for Columbine). Revista Liberdades, São Paulo, p. 142-143, dez. 2011 (Edição especial). Disponível em:

http://www.ibccrim.org.br/revista_liberdades_artigo/108-RESENHA-DEFILME. Acesso em 01/12/2016

GIDDENS, Anthony. A vida em uma sociedade pós-tradicional. In: BECK, Ulrich; GIDDENS, Anthony; LASH, Scott. Modernização Reflexiva: política, tradição e estética na ordem social moderna. Tradução de Magda Lopes. São Paulo: Editora da Universidade Estadual Paulista, 1997. p. 73134.

Sociologia. Tradução de Sandra Regina Netz. 4. ed. Porto Alegre: Artmed, 2005.

GRAZIANO SOBRINHO, Sergio Francisco Carlos. Cultura do Medo. In: SIDEKUM, Antonio; WOLKMER, Antonio Carlos; RADAELLI, Samuel Manica (Orgs.). Enciclopédia latino-americana dos direitos humanos. Nova Petrópolis, RS: Nova Harmonia, 2016, p. 139-144.

GONZÁLEZ ORDOVÁS, Maria José. La Ciudad em Clave de Riesgo. In: ROSILLO MARTÍNEZ, Alejandro et al. Teoria crítica dos direitos humanos no século XXI. Porto Alegre: EDIPUCRS, 2008. p. 437-460.

OLIVEIRA, Fabrício Roberto Costa; ZANGELMI, Arnaldo José. Modernidade e Reflexividade: Anthony Giddens e a interpretação do mundo contemporâneo. Isegoria - Ação Coletiva em Revista. Viçosa, 
CARDEMATORI, Daniela Mesquita Leutchuk de; LUZ, Marlise da Rosa. O medo como instrumento de legitimação da atuação repressiva do estado. Revista Eletrônica Direito e Política, Programa de Pós-Graduação Stricto Sensu em Ciência Jurídica da UNIVALI, Itajaí, v.12, n.3, $3^{0}$ quadrimestre de 2017. Disponível em: www.univali.br/direitoepolitica - ISSN $1980-7791$

Universidade Federal de Viçosa, 2011, v. 1, n. 2, p 111-123, set. de 2011/fev. de 2012.

PASTANA, Débora Regina. Medo e opinião pública no Brasil contemporâneo. Revista Estudos de Sociologia, Araraquara, v. 12, n. 22, p. 91-116, $2007 . \quad$ Disponível em: http://seer.fclar.unesp.br/estudos/article/view/350/214. Acesso em: 16 mar. 2016.

Medo, controle e segregação espacial: reflexões sobre a configuração urbana da cidade de São Paulo no atual estágio da modernidade. Mediações - Revista de Ciências Sociais. Londrina, v. 10, n. 2, p.183-198, jul/dez 2005. Disponível em:

http://www.uel.br/revistas/uel/index.php/mediacoes/article/view/2172/186 4. Acesso em: 29 set. 2016.

Submetido em: julho de 2017

Aprovado em: agosto de 2017 